\begin{tabular}{c} 
Volume and Issues Obtainable at Center for Sustainability Research and Consultancy \\
Responsible Education, Learning and Teaching in Emerging Economies \\
ISSN: 2708-4310 (E): 2708-4183 \\
Volume 1: No. 1, June 2019 \\
JSRᄃ \\
Journal homepage: www.publishing.globalcsrc.org/relate \\
\hline
\end{tabular}

\title{
Relationship of Achievement Goal Orientation of University Teachers with their Qualification at Work Engagement and Organizational Commitment
}

\author{
${ }^{1}$ Khadija Sittar, Sumaira Munawar \\ ${ }^{1}$ Assistant Professor, Lahore Leads University, Lahore, Pakistan: khadijasittar@gmail.com \\ ${ }^{2}$ Assistant Professor, Lahore Leads University, Lahore, Pakistan: sumairamunawar16@gmail.com

\begin{tabular}{l} 
ARTICLE DETAILS \\
\hline History \\
Revised format: May 2019 \\
Available Online: June 2019 \\
\hline Keywords \\
Achievement Goal Orientation, \\
Work Engagement, \\
Organizational Commitment
\end{tabular} \\ JEL Classification: \\ J20, D23, D29

\section{ABSTRACT} \\ The study was exploring the relationship between achievement goal \\ with teachers' qualifications at work engagement and organizational \\ commitment. Correlation research design was adopted along with \\ quantitative approach. Participants of the study were selected from \\ universities located in central Punjab from two districts (Lahore and \\ Faisalabad). Sample of the current study was taken 159 public and \\ private university teachers through stratified sampling technique. \\ Pearson r, one-way ANOVA was used to analyze the data. The \\ findings of the study indicated that there was a moderate positive \\ correlation between male and female teachers qualification. \\ Qualification wise difference was existed between public and \\ private university teachers regarding work engagement and \\ organizational commitment in terms of their qualification was \\ found.
}

\section{OPEN ACCESS}

(C) 2019 The authors, under a Creative Commons Attribution-

NonCommercial 4.0

Corresponding author's email address: khadijasittar@gmail.com

Recommended citation: Sittar, K. \& Munawar, S., (2019). Relationship of Achievement Goal Orientation of University Teachers with their Qualification at Work Engagement and Organizational Commitment. Responsible Education, Learning and Teaching in Emerging Economies, 1(1), 25-30

DOI: $10.26710 /$ relate.v1i1.1119

\section{Introduction}

Achievement orientations are directly associated with academic achievements and goals, modifications, and well-being of individuals. In achievement goal theory presented by Nicholls (1984); Ames and Ames(1984) Vande Walle (1997) and Dweck (1990) explained briefly that certain types of goals such as performance approach goals, performance avoidance goal and learning goals which individuals have capability to strive hard. Learning goals are referred to the development of competencies knowledge or skills for individual's intention. Dweck (1990) further added that the challenging tasks such as oppoetunity for learning, interpreting failure as a starting point are viewed by individuals as an opportunity with a learning goal orientation. Performance approach along with avoidance goals are referred as the tendency to be bothered with tremendous affirmation of demonstrated conduct from others. Van Yperen (2006) concluded that the assumed standards, for example, previous performance level, 
individual expectations are assumed as a set standard of comparing the performance norms of colleagues. These factors are called both internal and external factors. Vande Walle (1997) presented that ineffectiveness and incompetence are related to performance avoidance goals and high performance demonstration is related to performance goal approach.

Professional improvement activities and skills have a great impact for instructors and teachers to continuously enhance their knowledge and abilities. However, researchers such as Kwakman (2003); Lohman(2005); Opfer and Pedder(2011); Nitsche, Fasching, Dickhäuser and Dresel( 2013) ;Van Eekelen, Boshuizen and Vermunt (2006) indicates that teachers vary strongly in how actively they got engaged themselves in formal and informal learning activities such as in search of records, participation in workshops in- or out of doors the faculty, and soliciting for It is likely that teachers' motivation to take part in professional improvement activities are directly concerned to their achievement orientation.

Current study is conducted to identify goal and objective oriented profiles of teachers in Vocational and academic Educational expertise of the connection between objective orientation profiles and professional development activities. Beverborg (2015) reported a study and described that teachers were confronting with major academic reform within the current years; the implementation of "Competence Based Education". To raise this innovatory and new idea and to reinforce the connection with practical steps, the group of teachers composed of various disciplines worked together in different teams to efficiently prepare vocational training packages. Stoll, Wallace McMahon, Bolam, and Thomas (2006) conducted a research on involvement in expert improvement activities, in which implementation in educational improvement are hit by experimenting new teaching practicing, asking colleagues for feedback and acquiring statistics. This take a look at presents a contribution to the literature on intention orientations by using exploring goal orientation profiles inside the paintings area, especially for instructors. This is essential due to the fact cutting-edge research in the paintings contextual generally attention on linear relationships among unmarried purpose orientations, thereby neglecting the possibility of coexistence of different purpose orientations.

Chalofsky and Krishna (2009) further added that teacher engagement is defined as a wonderful and workrelated kingdom of thoughts consisting of power, dedication and absorption in the paintings Meaningfulness, dedication, and engagement: The intersection of a deeper degree of intrinsic motivation. It shows the attempt that teachers exert in teaching, and for that reason it's far intently related to their work overall performance. Ajzen(2001) contributed thattTeacher dedication is a hallmark of the psychological attachment to coaching, and it entails a sturdy choice and willingness to stay within the career. As it determines the renovation of teachers' electricity and enthusiasm for teaching, it is a crucial element for the destiny long-term success of character institutions and schooling as a whole. Thus, trainer engagement and instructor dedication reflect man or woman teachers' temporal orientation and attitudes towards coaching, with instructor engagement an outline of teachers' gift-orientated leisure of teaching, at the same time as dedication is destiny-orientated and anticipatory. They each make a contribution to a comprehensive know-how of instructors' psychological country through the years. In addition, they may be structurally just like the concept of mindset. This shows an internal condition of a person that indicates and provides guidelines to beliefs, emotions and behavioral approach.

Esen( 2011) indicated that There is a very close connection among organizational commitment and work engagement. Gallup Organization who's researched this courting in America discovered personnel who are integrated with work are unswerving for enterprise approximately psychological too and excited and inclined. Gostick and Elton (2011) explored that workers and employees who are incorporated with work provide strength in companies' progressive development, showing higher overall performance, they rely organizations success, they take duties. Employees make of their corporations, they take the time and spend time as expectations, they've lower pressure and work stress, their task satisfactions are high, they use decrease medical facilitates, they attain permission decrease than others they're effective and they work in organization long term. There are a few studies approximately relationship among organizational 
commitment and integration with work. Further study was conducted to explore that a private variables direct outcomes, organizational variables direct effects and organizational variables oblique effects for private variables high-quality and significant (Kavgac1,2014).

\section{Objectives of the study}

Following objectives were achieved in this study. To;

- Explore the relationship of achievement goal orientation and work engagement.

- Explore the relationship of achievement goal orientation and organizational commitment.

- Identify the difference in achievement goal orientation of teachers with work engagement and organizational commitment on the basis of qualification.

\section{Research Questions}

The research questions of the study were as following.

- What is the relationship between achievement goal orientation and work engagement of teachers?

- What is the relationship achievement goal orientation and organizational commitment?

- What is the difference between achievement goal orientations of teachers with work engagement and organizational commitment on the basis qualification?

\section{Research Methodology}

In order to find out relationship between the variables a correlation research desigh was used in this study.

\subsection{Population}

Population of the study were consisted of all public and private universities teachers of central Punjab. There are 30 general type universities "( 15 public, and 15 private)" in Punjab.

\subsection{Sample and sampling technique}

Sample was selected through stratified sampling technique. Following three stages were formed for sample selection.

Stage 1: 4 general type universities (2 public and 2 private) were randomly selected.

Stage 2; teachers were selected by using censes sampling technique according their qualifications (M.A, M. Phil, Ph. D)

\subsection{Instrumentation}

Questioner was used for data collection. The researcher was used a self-compiled questionnaire for data collection. The questionnaire was consisted of five point likert scales. Questionnaire was consisted achievement goal orientation, work engagement and organizational commitment.

\subsection{Data collection}

Researcher was visit the universities herself for data collection. Data from selected teachers from 4 general type universities ( 2 public) and ( 2 private) were collected personally by the researcher.

\subsection{Data Analysis}

Data were analysed by using inferential statistic and descriptive statistics. Pearson-r/Regression was applied to explore the correlation between variables. Mean and Standard Deviation was calculated. At the third stage t-test was used in order to see the significance of the difference among achievement goal orientation university teachers for work engagement and organizational commitment. 


\section{Results}

Table 1: Qualification wise Sample Distribution

\begin{tabular}{|l|l|l|}
\hline \multicolumn{1}{|c|}{ Qualification } & Frequency & Percentage \\
\hline M. A & 10 & 6.3 \\
\hline M. Phil & 79 & 49.7 \\
\hline Ph. D & 70 & 44.0 \\
\hline Total & 159 & 100.0 \\
\hline
\end{tabular}

Table showed that teachers on the basis of qualification were selected. It showed that $10(6.3 \%)$ teachers had M.A qualification and 79(49.7\%) teachers had M. Phil and 70(44\%) teachers Ph. D qualification.

Table 2: Relationship between Work Engagement and Achievement Goal Orientation

\begin{tabular}{|l|l|l|l|}
\hline Variables & $N$ & $r$-value & Sig. \\
\hline $\begin{array}{l}\text { Work Engagement } \\
\text { Achievement Goal Orientation }\end{array}$ & 159 & .254 & .001 \\
\hline
\end{tabular}

Table shows the relationship between work engagement and achievement goal orientation in university teachers. Results show that positive weak significant relationship among work engagement and achievement goal orientation. R-value shows weak positive significant relationship $r=.254$ at $p<.05$ among two variables.

Table 3: Relationship between Organizational commitment and achievement goal orientation

\begin{tabular}{|l|l|l|l|}
\hline Variables & $N$ & $r$-value & Sig. \\
\hline $\begin{array}{l}\text { Organizational commitment } \\
\text { achievement goal orientation }\end{array}$ & 159 & .354 & .001 \\
\hline
\end{tabular}

Table shows the relationship between organizational commitment and achievement goal orientation in university teachers. Results show that positive weak significant relationship among organizational commitment achievement goal orientation. R-value shows weak positive significant relationship $r=.354$ at $p<.05$ among two variables.

Table 4: Correlation between Organizational Commitment and Work Engagement

\begin{tabular}{|l|l|l|l|}
\hline Variables & $N$ & $r$-value & Sig. \\
\hline $\begin{array}{l}\text { Organizational commitment } \\
\text { and Work engagement }\end{array}$ & 159 & .554 & .001 \\
\hline
\end{tabular}

Table shows the relationship between organizational commitment and work engagement in university teachers. Results show that positive weak significant relationship among organizational commitment and work engagement. R-value shows weak positive significant relationship $r=.354$ at $p<.05$ among two variables.

Table 5: Difference between Achievement Goal Orientation on the basis of Teachers' Qualification

\begin{tabular}{|l|l|l|l|l|l|}
\hline & SS & $d f$ & $M S$ & F & Sig. \\
\hline Between Groups & 14.545 & 30 & .485 & 1.450 & .081 \\
\hline Within Groups & 42.813 & 128 & .334 & & \\
\hline Total & 57.358 & 158 & & & \\
\hline
\end{tabular}


Table shows the difference among teachers by applying one-way ANOVA about achievement goal orientation on the basis of qualification. There was no significant difference $F(158)=1.450), p=.081$ in achievement goal orientation of teachers on qualifications (M.A, M. Phil, Ph. D).

Table 6: Difference of Work engagement on the basis of Teachers' Qualification

\begin{tabular}{|l|l|l|l|l|l|}
\hline & $S S$ & $D f$ & $M S$ & $F$ & Sig. \\
\hline Between Groups & 11.051 & 30 & .368 & 1.018 & .451 \\
\hline Within Groups & 46.307 & 128 & .362 & & \\
\hline Total & 57.358 & 158 & & & \\
\hline
\end{tabular}

Table shows the difference among teachers about work engagement on the basis of qualification. No significant difference was found $F(158)=1.018), p=.451$ in work engagement of teachers on qualifications (M.A, M. Phil, Ph. D).

Table 7 : Difference of Organizational Commitment regarding Teachers' Qualification

\begin{tabular}{|l|l|l|l|l|l|}
\hline & SS & $d f$ & $M S$ & $F$ & Sig. \\
\hline Between Groups & 13.657 & 27 & .506 & 1.516 & .065 \\
\hline Within Groups & 43.702 & 131 & .334 & & \\
\hline Total & 57.358 & 158 & & & \\
\hline
\end{tabular}

Table shows the difference among teachers about "organizational commitment on the basis of qualification". There was no significant difference $F(158)=1.516), p=.65$ in organizational commitment of teachers on qualifications (M.A, M. Phil, Ph. D).

\section{Conclusion}

Individuals' well-being, modifications, goals and academic achievement is directly related with achievement orientations. In this present study work engagement and organizational commitment with achievement goal orientation is associated significantly weak and moderate respectively. Work engagement is moderately associated with organizational commitment at university level. Teachers from public and private universities on the basis of qualification have no differences in opinions regarding goal orientation, organizational commitment and work engagement. Therefore it is recommended that teachers' might be given goal oriented tasks in order to enhance commitment with institutions.

\section{References}

